\title{
What do GDPs think about fluoridation?
}

\section{Attitudes to water fluoridation in general dental practice in the North East of England}

\section{R. J. Lowry and G. Adams Br Dent J 2004; 196: 423-424}

\section{Objective}

To find out the knowledge of, and attitudes towards, water fluoridation of a sample of general dental practitioners working in the North East of England.

\section{Design}

Anonymous, self-completed postal questionnaire.

\section{Setting}

North East of England, both a fluoridated and non-fluoridated area.

\section{Subjects and methods}

Following a small pilot survey, questionnaire to 79 general dental practitioners (44 in a non-fluoridated area, 35 in an area supplied with fluoridated water at one part per million) contracted to provide National Health Service (NHS) treatment in the North East of England.

\section{Results}

Fifty-five general dental practitioners returned questionnaires (a $70 \%$ response rate). Most respondents supported the principle of water fluoridation. Over half of the respondents indicated that they would benefit from more information and training on the issue of water fluoridation. There were marked differences in knowledge and attitudes to fluoridation between dental principals and associates. The sample was evenly split about what to do with a parent who was unsure about (whether to support) fluoridation even after the dentist had discussed the issue and answered questions.

\section{Conclusions}

The majority of general dental practitioners support water fluoridation although some lack knowledge and expertise which might inhibit advocacy of it.

\section{IN BRIEF}

- Dentists are relative strangers to controversy.

- Dentists may feel uncomfortable discussing controversial issues.

- Individual dentists may take some comfort from knowing how other colleagues feel.

\section{COMMENT}

This interesting paper conducted in the North East of England indicates that the majority of general dental practitioners support water fluoridation, although over half of the sample would like further training in how to advocate it. Would such efforts be worthwhile?

A number of surveys have examined the public's trust in doctors, nurses, dentists and other professions and occupational groups. For example, the MORI Social Research Institute has been tracking public trust in the professions for 20 years using samples of around 2,000 adults aged 15 years and above. Trust in the medical profession has risen steadily since 1983 from $82 \% 20$ years ago to $91 \%$ in 2003. In contrast, politicians, journalists and government ministers were voted least trustworthy with no more than one in five $(20 \%)$ of the sample trusting them to tell the truth. A similar study was conducted in 2002 for BBC Radio 4's Today programme in which 6,722 listeners selected their three most respected and three least respected professions and occupations from a list of 92 . Doctors and nurses were ranked 1 st and 2 nd, paramedics 5 th, and dentists 29th, while advertising executives, journalists, government ministers and MPs were ranked 86, 88, 90 and 92 respectively.

These data support the authors' contention that if new water fluoridation schemes are to be implemented, the support of all health professionals including general dental practitioners will be vital and of practical help. The House of Lords recently agreed, by a majority of 122, to support the Government proposal to place decisions about water fluoridation with health authorities rather than, as at present, with water companies. Subject to satisfactory passage of the Water Bill through the House of Commons, it does seem possible that some new schemes in areas of high dental need might be forthcoming. In which case how can we help GDPs to become involved? First, the authors draw attention to the British Dental Association's excellent 'fact file' on fluoridation. Although only $30 \%$ of the respondents had previously read it, all of them found it useful. Secondly, local consultants in dental public health have an important role not only in providing their practitioner colleagues with relevant and up to date information on water fluoridation but also in helping their colleagues to hone their advocacy skills, one of the key skills within the speciality of dental public health. The authors should be congratulated for bringing these issues to our attention.

Professor M. A. Lennon, School of Clinical Dentistry,

University of Sheffield

doi:10.1038/sj.bdj.4811137 